\title{
Miltefosine Suppresses Inflammation in a Mouse Model of Inflammatory Bowel Disease
}

\author{
Auke P. Verhaar, BSC, ${ }^{*+}$ Manon E. Wildenberg, PhD, ${ }^{*}$ Anje A. te Velde, PhD, ${ }^{*}$ Sybren L. Meijer, MD, \\ Anne Christine W. Vos, MD, ${ }^{+}$Marjolijn Duijvestein, MD, PhD, ${ }^{+}$Maikel P. Peppelenbosch, PhD, ${ }^{\S}$ \\ Daniel W. Hommes, MD, PhD, ${ }^{t, l}$ and Gijs R. van den Brink, MD, PhD*
}

\begin{abstract}
Background: The repertoire of immunomodulators that can be used for the treatment of inflammatory bowel disease is limited. The use of these drugs is further restricted by the occurrence of side effects in a proportion of patients. Miltefosine (hexadecylphosphocholine) is a lipid drug developed in the 1980s for the treatment of cancer but is nowadays best known for its application in the oral treatment of leishmaniasis. Although the exact mechanism of action of miltefosine has yet to be elucidated, the drug has previously been shown to inhibit phospholipases and protein kinase C, both key components of proproliferative signal transduction in T cells.
\end{abstract}

Methods: Stimulated peripheral blood lymphocyte were treated with miltefosine, and proliferation was measured. We use the CD45RB ${ }^{\text {high }}$ T-cell transfer colitis model to investigate the effect of miltefosine treatment on intestinal inflammation. Effects on the severity of colitis were studied by histochemical and immunohistochemical staining, and cytokine levels were determined using a cytokine bead array.

Results: Miltefosine inhibited T-cell proliferation in vitro. In the transfer model, miltefosine significantly ameliorated the severity of colitis as measured by clinical, (immuno)histochemical, and biochemical parameters.

Conclusions: Miltefosine inhibits T-cell proliferation and effectively reduces inflammation in the T-cell transfer model. The drug may therefore be a candidate immunomodulator for inflammatory bowel disease.

(Inflamm Bowel Dis 2013;19:1974-1982)

Key Words: inflammatory bowel disease, CD4CD45 mouse transfer model, miltefosine, hexadecylphosphocholine, immunomodulator, inflammation

A limited number of drugs is available for the treatment of inflammatory bowel disease. In Crohn's disease for example, glucocorticoids can be used for remission induction but are generally not advised for long-term treatment because of their limited value for remission maintenance and important side effects. Thiopurines and methotrexate are widely used but unfortunately only work in a proportion of patients and are sometimes poorly tolerated. If tolerated, the drugs can show important side effects such as bone marrow suppression or pancreatitis. Even if patients are started on anti-tumor necrosis factor (TNF) antibodies, immunomodulators are often used as cotreatment to increase the efficacy of the antiTNF and prevent the development of anti-TNF neutralizing anti-

Received for publication February 15, 2013; Accepted March 11, 2013.

From the *Department of Gastroenterology and Hepatology, Tytgat Institute for Liver and Intestinal Research, Academic Medical Center, Amsterdam, the Netherlands; 'Department of Gastroenterology and Hepatology, Leiden University Medical Center, Leiden, the Netherlands; ${ }^{\dagger}$ Department of Pathology, Academic Medical Center, Amsterdam, the Netherlands; ${ }^{\S}$ Department of Gastroenterology and Hepatology, Erasmus MC, Rotterdam, the Netherlands; and "Center for Inflammatory Bowel Diseases, University of California Los Angeles, Los Angeles, California.

The authors have no conflicts of interest to disclose.

Reprints: Gijs R. van den Brink, MD, PhD, Department of Gastroenterology and Hepatology, Room C2-115, Academic Medical Center, Meibergdreef 9, 1105 AZ Amsterdam, the Netherlands (e-mail: g.r.vandenbrink@amc.uva.nl).

Copyright (C) 2013 Crohn's \& Colitis Foundation of America, Inc.

DOI 10.1097/MIB.0b013e3182917a2b

Published online 27 June 2013. bodies. Therefore, there is a clear need for the identification of novel candidate immunomodulators for remission induction or maintenance in patients with inflammatory bowel disease (IBD).

Miltefosine is an ether lipid drug originally designed in the eighties for the treatment of cancer. Systemic treatment with the drug has been tested in phase $\mathrm{I}^{1}$ and phase II clinical trials in advanced colorectal cancer, ${ }^{2}$ soft tissue sarcoma, ${ }^{3}$ squamous cell head, and neck cancer. ${ }^{4}$ In oncology, miltefosine only made it a phase III trial that showed effectiveness as a topical palliative treatment for cutaneous metastases of breast cancer. ${ }^{5}$ In the mean time, however, it was found that miltefosine showed activity against Leishmania in animal models ${ }^{6}$ and clinical trials showed spectacular therapeutic efficacy in patients with visceral leishmaniasis. $^{7,8}$ Miltefosine is well absorbed, has a half-life of 7 days, ${ }^{9}$ and is generally well tolerated at a dose of 100 to $150 \mathrm{mg}$ /day that is used for the treatment of leishmaniasis. The most important side effects of doses up to $150 \mathrm{mg}$ /day are mild-to-moderate nausea and vomiting that occur mostly in the first 2 weeks of the treatment and are often transient. ${ }^{7,8}$ Furthermore, mild and reversible elevations in the aminotransferases and creatinine have been described., ${ }^{7,8}$

The mechanism of action of miltefosine is incompletely understood. Miltefosine is chemically related to membrane phospholipids and generally believed to act by modulating signaling events at cellular membranes. ${ }^{10}$ It has been reported that miltefosine inhibits phospholipase $\mathrm{C}$, phospholipase $\mathrm{D}$, and protein kinase C. ${ }^{10}$ 
Since activation of $\mathrm{T}$ cells critically depends on activation of phospholipase $\mathrm{C}$ and protein kinase $\mathrm{C}$, we hypothesized that treatment with miltefosine might inhibit $\mathrm{T}$-cell activation. Indeed, it has previously been reported that miltefosine inhibits T-cell proliferation in mixed lymphocyte reactions and showed inhibitory activity in an ovalbumin-induced mouse model of delayed-type hypersensitivity in mice $^{11}$ and in patients with atopic dermatitis. ${ }^{12}$

Here, we find that miltefosine inhibits both phytohemagglutinin and staphylococcal enterotoxin B-mediated T-cell proliferation. Our experiments show that treatment of mice with miltefosine ameliorates severity of a T-cell-dependent murine model of IBD.

\section{MATERIALS AND METHODS}

\section{Reagents and Antibodies}

Anti-mouse CD3 (A0452) biotin-labeled goat anti-rat and streptavidin-horseradish peroxidase complex were purchased from DAKO (Heverlee, Belgium). A poly-horseradish peroxidase-labeled anti-rabbit antibody (DPVR110HRP) was purchased from Immunologic (Duiven, the Netherlands). FITC rat anti-mouse Ly-6G (553127), FITC rat anti-mouse CD45RB (553099), and PE-Cy5 rat anti-mouse CD4 (553050) were purchased from BD Pharmingen (Breda, The Netherlands). F4/80 rat anti-mouse, clone BM8 (T2006) was purchased from BMA Biomedicals (Augst, Switzerland). Rabbit $\mathrm{F}\left(\mathrm{ab}^{\prime}\right) 2$ anti-rat IgG (6130-01) was purchased from Southern Biotech (Birmingham, Alabama). Miltefosine was purchased from Cayman Chemical (Huissen, The Netherlands). Sheep anti-rat IgG Dynabeads were purchased from Invitrogen (Oslo, Norway)

\section{Cells}

Human peripheral blood lymphocytes (PBLs) were isolated from whole blood of healthy volunteers by Ficoll-Isopaque density gradient centrifugation. After washing, monocytes were separated from lymphocytes by percoll density gradient centrifugation. The lymphocytes were cultured in Iscove's Modified Dulbecco's Medium (Gibco, Verviers, Belgium) supplemented with $10 \%$ heat-inactivated fetal calf serum. For proliferation experiments, cells were stimulated for 24 hours. Lymphocytes were stimulated with phytohemagglutinin (PHA) $(10 \mu \mathrm{g} / \mathrm{mL})$ or Staphylococcal enterotoxin B (SEB) $(100 \mathrm{ng} / \mathrm{mL})$. Proliferation was measured using a ${ }^{3} \mathrm{H}$-thymidine incorporation assay. Mouse splenocytes were isolated from spleen from C57BL/6 mice. Spleens were homogenized and passed through a $70-\mu \mathrm{m}$ strainer.

\section{Mouse Experimental Colitis CD45RB ${ }^{\text {high }}$ Transfer Model}

C.B-17 SCID mice and wild-type BALB/c mice were ordered from Harlan (Boxmeer, the Netherlands). Transfer of $\mathrm{CD}_{45 \mathrm{RB}^{\text {high }}} \mathrm{CD}^{+}$cells was performed as previously described by Read and Powrie. ${ }^{13}$ In short, for every 3 SCID mice, $\mathrm{CD}_{45 \mathrm{RB}^{\text {high }}}$ cells were isolated from the spleen of a single wildtype BALB/c mouse. A single cell suspension was created by forcing the spleens through a cell strainer. Erythrocytes were removed by adding erythrocyte lysis buffer followed by negative depletion of macrophages, $\mathrm{B}$ cells, and $\mathrm{CD}^{+}$cells using magnetic beads. The remaining $\mathrm{CD}^{+}$cell-enriched cell suspension was labeled and $\mathrm{CD} 45 \mathrm{RB}^{\text {high }}$ and $\mathrm{CD} 45 \mathrm{RB}^{\text {low }}$ cells were isolated on a FACS sorter. Colitis was induced by injecting $4 \times 10^{5}$ $\mathrm{CD} 45 \mathrm{RB}^{\text {high }}$ cells intraperitoneally. Control mice received a combination of $4 \times 10^{5} \mathrm{CD} 45 \mathrm{RB}^{\text {high }}$ cells and $2 \times 10^{5} \mathrm{CD}^{2} 5 \mathrm{RB}^{\text {low }}$ cells. The inflammation developed over a period of 8 to 10 weeks. Two groups of 10 SCID mice each were injected with $\mathrm{CD} 4{ }^{+} \mathrm{CD} 45 \mathrm{RB}{ }^{\text {high }}$ cells, and 1 group of 10 mice was injected with a combination of $\mathrm{CD}^{+} \mathrm{CD} 45^{\text {high }}$ and $\mathrm{CD} 4^{+} \mathrm{CD} 45 \mathrm{RB}^{\text {low }}$ cells. Because the first 2 groups have a reconstituted T-cell repertoire lacking regulatory $\mathrm{T}$ cells, they will develop colitis. The last group does have regulatory $\mathrm{T}$ cells (contained in the $\mathrm{CD} 4{ }^{+} \mathrm{CD} 45 \mathrm{RB}^{\text {low }}$ compartment), will not develop colitis, and acts as a control group.

Miltefosine was dissolved in $10 \%$ dimethyl sulfoxide in phosphate-buffered saline (PBS). Each mouse received $50 \mathrm{mg} / \mathrm{kg}$ miltefosine twice weekly in $200 \mu \mathrm{L}$ solution by oral gavage or in the case of the positive control group, $200 \mu \mathrm{L} 10 \%$ dimethyl sulfoxide in PBS. The mice were euthanized by $\mathrm{CO}_{2}$ inhalation followed by removal of the spleen and colon.

Body weights were recorded 3 times a week, and wasting disease progression was calculated by percentage of weight loss from initial body weight. Animals were withdrawn from the study when the weight loss was more than $15 \%$ compared with the starting weight. Both the colon and the spleen were removed and weighed. Two independent investigators blinded for treatment allocation scored the colons for stool consistency, visible fecal blood, and macroscopic inflammation using a scale of 0 to 3 per item with a maximum score of 9 . Tissue weights were recorded and used as an index of disease-related intestinal wall thickening. Colons were subsequently divided longitudinally into 2 parts: one part was immediately frozen in liquid nitrogen for protein extraction and cytokine determination, whereas the second part was stored in formalin and embedded in paraffin for (immuno) histological evaluation.

\section{Histological Analysis}

Hematoxylin and eosin sections were blindly scored by an independent experienced gastrointestinal pathologist (S.L.M.). The histology damage score was calculated as the total score of points that were scored on 6 criteria. (A) Leukocyte infiltration: $0=$ normal, $1=$ increase in mucosa, $2=$ increase in mucosa + submucosa, 3 = extending into tunica muscularis. (B) Loss of goblet cells: $0=$ none, $1=<10 \%$ depletion, $2=10 \%$ to $50 \%$, $3=>50 \%$. (C) Crypt loss: $0=$ none, $1=<10 \%$ loss, $2=10 \%$ to $50 \%, 3=>50 \%$. (D) Epithelial hyperplasia: $0=$ normal, $1=$ slight, $2=2$ to $3 \times$ increased crypt length, $3=>3 \times$ increase. (E) Ulceration: $0=$ none, $4=$ present. $(\mathrm{F})$ Crypt abcesses: $0=$ none, $4=$ present. The histological damage score ranged from 0 points to a maximum of 20 points.

\section{Immunohistochemistry}

For immunohistochemical staining, slides were deparaffinized, dehydrated, and immersed in $1.5 \% \mathrm{H}_{2} \mathrm{O}_{2}$ in PBS for 

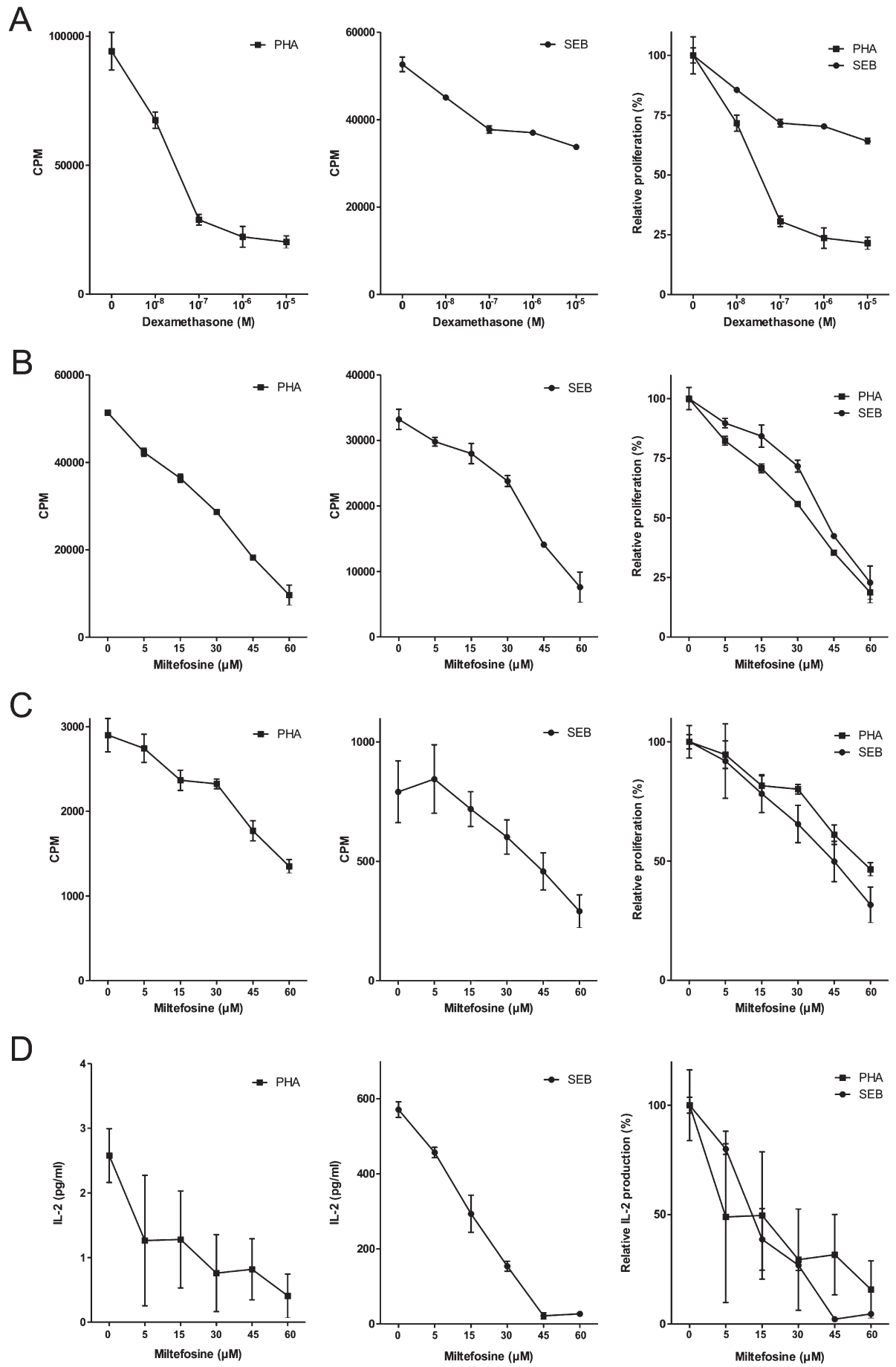

FIGURE 1. Miltefosine inhibits T-cell proliferation. A, Human PBL were stimulated with either PHA (10 $\mu \mathrm{g} / \mathrm{mL})$ or SEB (100 ng/mL) for $24 \mathrm{hours}$ in the presence of different doses of dexamethasone. Data shown are absolute and relative proliferation as measured by ${ }^{3} \mathrm{H}$ incorporation. $\mathrm{PBL}$ treated with SEB show partial steroid insensitivity as previously described. B, Human PBL were stimulated with either PHA (10 $\mu \mathrm{g} / \mathrm{mL})$ or SEB $(100 \mathrm{ng} / \mathrm{mL})$ for 24 hours in the presence of different doses of miltefosine. Data shown are absolute and relative proliferation as measured by ${ }^{3} \mathrm{H}$ incorporation. $\mathrm{PBL}$ treated with SEB show no insensitivity to miltefosine. C, Mouse splenocytes were stimulated with either PHA (10 $\mu \mathrm{g} / \mathrm{mL})$ or SEB (100 ng/mL) for 24 hours in the presence of different doses of miltefosine. Data shown are absolute and relative proliferation as measured by ${ }^{3} \mathrm{H}$ incorporation. Mouse splenocytes show sensitivity to miltefosine that is similar to humans. Each data point represents the mean and standard error of the mean of 4 independent samples. D, Human PBL IL-2 cytokine levels as measured by enzyme-linked immunosorbent assay. Human PBL were stimulated with either PHA $(10 \mu \mathrm{g} / \mathrm{mL})$ or SEB $(100 \mathrm{ng} / \mathrm{mL})$ for 48 hours in the presence of different doses of miltefosine. Both the production of IL-2 by PHA-stimulated PBL and by SEB-stimulated PBL are sensitive to miltefosine. Each data point represents the mean and standard error of the mean of 4 independent samples. 
30 minutes. Different methods of antigen retrieval were used for the different antibodies. For the F4/80 staining, slides were cooked for 10 minutes in $0.1 \mathrm{M}$ sodium citrate ( $\mathrm{pH} 6$ ), and for the $\mathrm{CD} 3$ staining, they were cooked for 10 minutes in Tris-EDTA buffer $(10 \mathrm{mM}$ Tris, 1 mM EDTA [pH 9]). For the Ly6G staining, antigen retrieval was performed by incubation of the slide in $0.025 \%$ pepsin in 0.1 $\mathrm{M} \mathrm{HCl}$ at $37^{\circ} \mathrm{C}$ for 15 minutes. Subsequently, slides were blocked with Teng-T (10 mM Tris, $5 \mathrm{mM}$ EDTA, $0.15 \mathrm{M} \mathrm{NaCl}, 0.25 \%$ gelatin, $0.05 \%$ [vol/vol] Tween-20, $\mathrm{pH} 8.0$ ) for 30 minutes, followed by incubation overnight at $4{ }^{\circ} \mathrm{C}$ with the primary antibody in PBS with $0.1 \%$ Triton X-100\% and $1 \%$ bovine serum albumin. For detection of F4/80, an avidin-biotin detection system was used. Secondary antibodies were diluted in PBS with $10 \%$ human serum and incubated for $1 \mathrm{~h}$ at room temperature. Slides were then incubated for $1 \mathrm{~h}$ with horseradish peroxidase-conjugated avidin-biotin complex. For the detection of CD3 and Ly6G, the BrightVision detection system (Immunologic) was used. Peroxidase activity was detected with Sigma Fast 3,3-diaminobenzidine Tablets (D4293; Sigma). Sections were counterstained with hematoxylin, dehydrated, and mounted with Pertex (00801; Histolab Products AB, Gothenburg, Sweden). Macrophages, neutrophils, and T cells were counted blindly in 10 intercrypt spaces per mouse.

\section{Cytokine Measurements}

Human PBL were seeded in a 96-well plate and treated and stimulated for 48 hours. IL-2 cytokine levels were determined by enzyme-linked immunosorbent assay (Biolegend, San Diego, California) according to the manufacturer's instructions.

Cytokine levels in mice were determined in colon mucosa. Colon homogenates were obtained using a Heidolph SilentCrusher

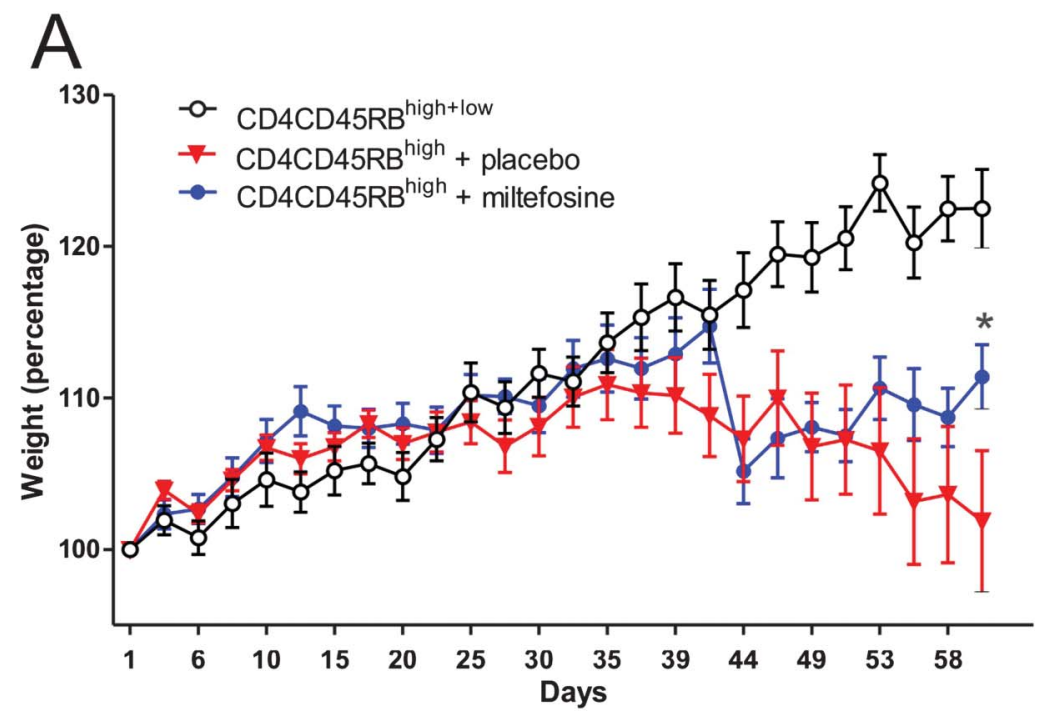

B
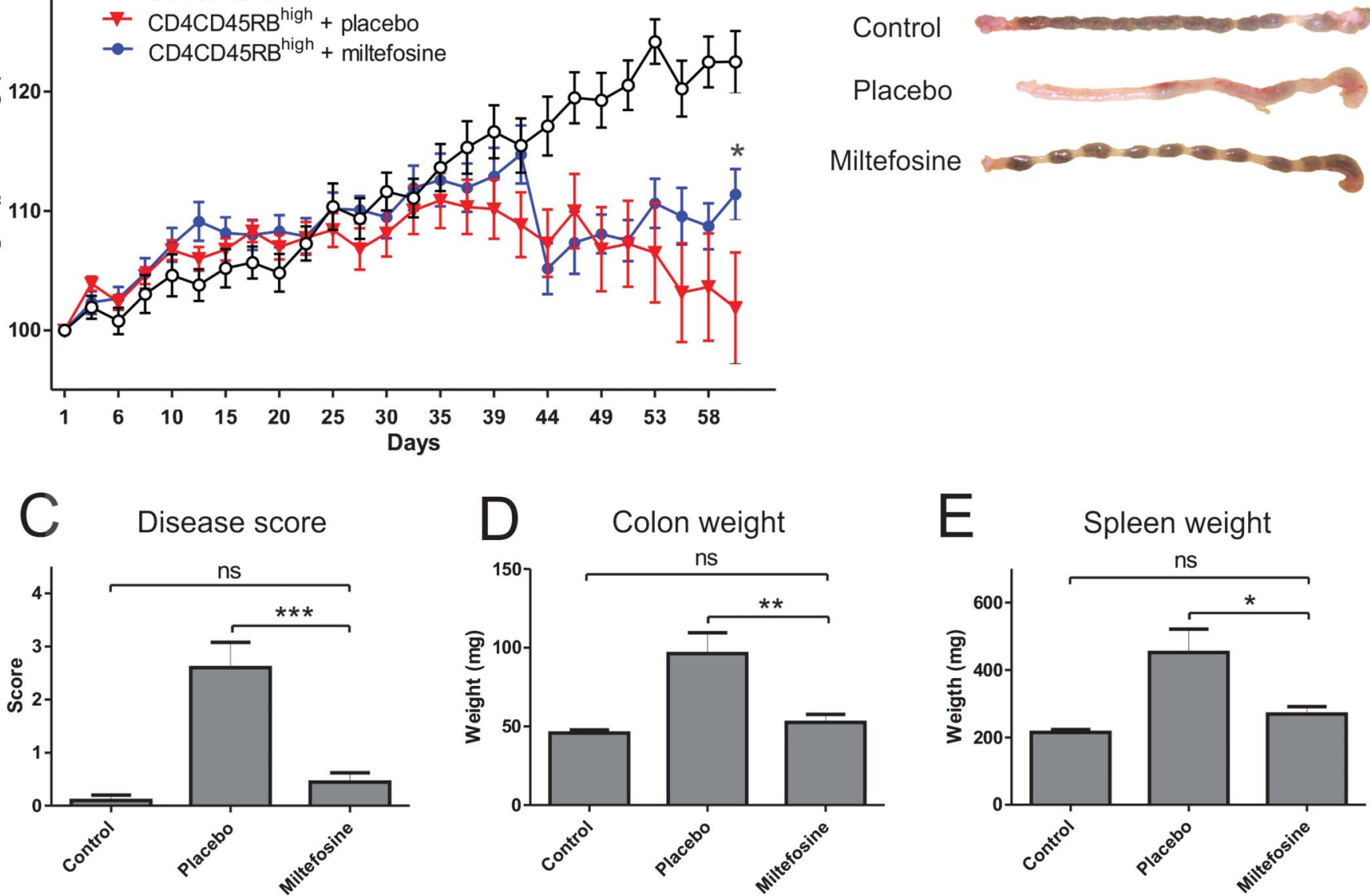

FIGURE 2. Miltefosine treatment reduces inflammation in $\mathrm{CD}^{+}{ }^{+} \mathrm{CD} 45 \mathrm{RB}$ high transfer model. A, Average weight of each group of mice as a percentage of the starting weight during the course of the experiment. The control group (black open circle) received both $C D 4^{+} \mathrm{CD} 45 \mathrm{RB}{ }^{\text {high }}$ and $\mathrm{CD} 4{ }^{+} \mathrm{CD} 45 \mathrm{RB}{ }^{\text {low }}$ and did not develop inflammation. Both the placebo treatment group (red inverted triangle) and the miltefosine-treated group (50 mg/kg twice weekly) (blue closed circle) received $C D 4+C D 45 R B^{\text {high }}$ only. $B$, Representative examples of colons from mice in the indicated groups. The colon in the colitis group is clearly inflamed and void of stool, whereas the colon of the treated group shows no signs of inflammation and is filled with solid pellets comparable to the healthy control. C, Disease score for different groups. $D$, Colon weight. E, Spleen weight. ${ }^{*} P<0.05$, ${ }^{* *} P<0.01$, ${ }^{* * *} P<0.001$. Control $=\mathrm{CD} 4{ }^{+} \mathrm{CD} 45 \mathrm{RB}^{\text {high+low }}$, placebo $=\mathrm{CD}^{+}{ }^{+} \mathrm{CD} 45 \mathrm{RB}^{\text {high }}+$ placebo, miltefosine $=\mathrm{CD}^{+} \mathrm{CD} 45 \mathrm{RB}^{\text {high }}+$ miltefosine. 

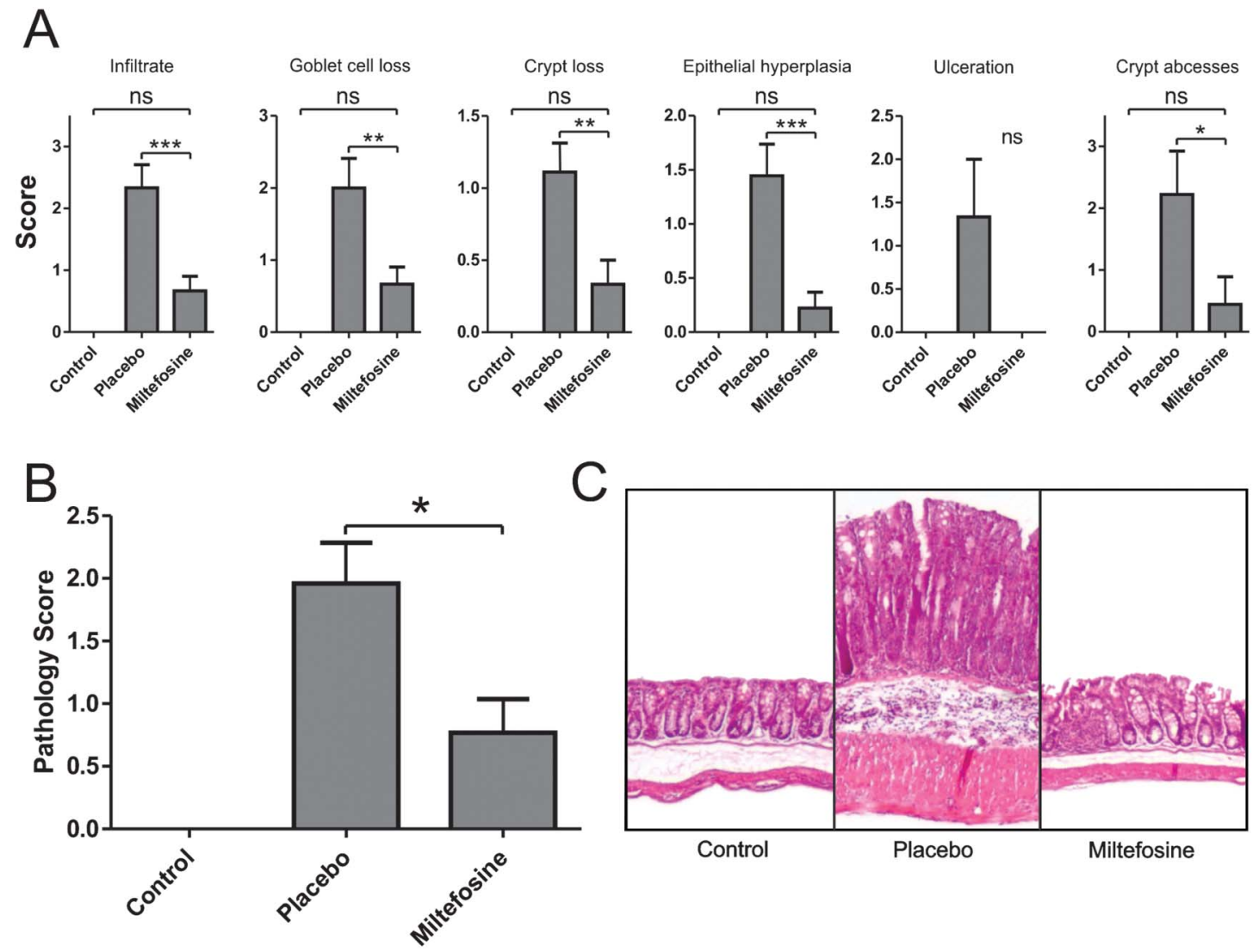

FIGURE 3. Miltefosine treatment improves the histopathological score of colitis. A, Individual components of the histopathological colitis score. B, Total score. C, Representative images of hematoxylin and eosin-stained slides of colons from mice in the indicated groups. Control $=$ $\mathrm{CD} 4{ }^{+} \mathrm{CD} 45 \mathrm{RB}^{\text {high }+ \text { low }}$, placebo $=\mathrm{CD} 4{ }^{+} \mathrm{CD} 45 \mathrm{RB}^{\text {high }}+$ placebo, miltefosine $=\mathrm{CD} 4{ }^{+} \mathrm{CD} 45 \mathrm{RB} \mathrm{B}^{\text {high }}+$ miltefosine. Original magnification in $\mathrm{C}: \times 100$. ${ }^{*} P<$ $0.05,{ }^{* *} P<0.01,{ }^{* * *} P<0.001$.

$\mathrm{M}$ homogenizer at $4^{\circ} \mathrm{C}$ in $500 \mu \mathrm{L}$ lysis buffer (Cell Signaling Technology, Beverly, California) supplemented with protease inhibitors (Roche, Almere, the Netherlands). Samples were centrifuged at $24,000 \mathrm{~g}$ for 10 minutes at $4^{\circ} \mathrm{C}$ and stored at $-80^{\circ} \mathrm{C}$ until cytokine measurement. Protein content was determined using the BCA Protein Assay (Thermo Scientific Pierce, Etten-Leur, the Netherlands), and cytokine levels in homogenates were measured using the Cytometric Bead Array System (BD Biosciences, Breda, the Netherlands) according to the manufacturer's instructions.

\section{Statistical Analysis}

Results are shown as means \pm standard error of the mean unless otherwise indicated. For statistical analysis, 1-way analysis of variance was used followed by a Bonferroni posttest. Results were considered significant when $P<0.05$.

\section{RESULTS}

\section{Miltefosine Inhibits T-cell Proliferation}

Previous studies have shown that miltefosine treatment inhibits T-cell proliferation in a mixed lymphocyte reaction. ${ }^{11} \mathrm{We}$ used 2 stimuli that directly activate the T-cell receptor in different ways to confirm this observation. The concentration miltefosine used is within physiologically relevant range. ${ }^{9}$ PHA binds CD3 directly ${ }^{14}$ and nonspecifically. This results in the potential activation of all $\mathrm{T}$ cells. SEB is a superantigen that activates a large proportion of the $\mathrm{T}$-cell population by binding directly to the $\mathrm{V} \beta$ chain of the T-cell receptor, activating over $20 \%$ of the total T-cell repertoire. ${ }^{15} \mathrm{We}$ chose SEB in addition to PHA as it has previously been described that SEB induces steroid resistance in T cells. ${ }^{16} \mathrm{~T}$ cells stimulated with PHA were highly sensitive to dexamethasone, whereas SEB induced a state of partial steroid resistance as described (Fig. 1A). In contrast, T-cell proliferation induced with PHA and SEB was equally sensitive to miltefosine (Fig. 1B). We subsequently isolated mouse splenocytes from C57BL/6 mice and stimulated these with both PHA and SEB. The sensitivity of mouse splenocytes to both PHA and SEB is less than that of human cells (Fig. 1C), but as in the human cells, PHA and SEB showed a similar sensitivity to miltefosine treatment. And finally, we measured IL-2 cytokines levels in the medium of PHA-stimulated or SEB-stimulated human PBL treated with different doses of miltefosine (Fig. 1D). IL-2 secretion by both PHA-stimulated and SEB-stimulated PBL showed sensitivity to miltefosine treatment. Stimulation of human PBL with PHA results in very low levels of IL-2 secretion. ${ }^{17}$ 

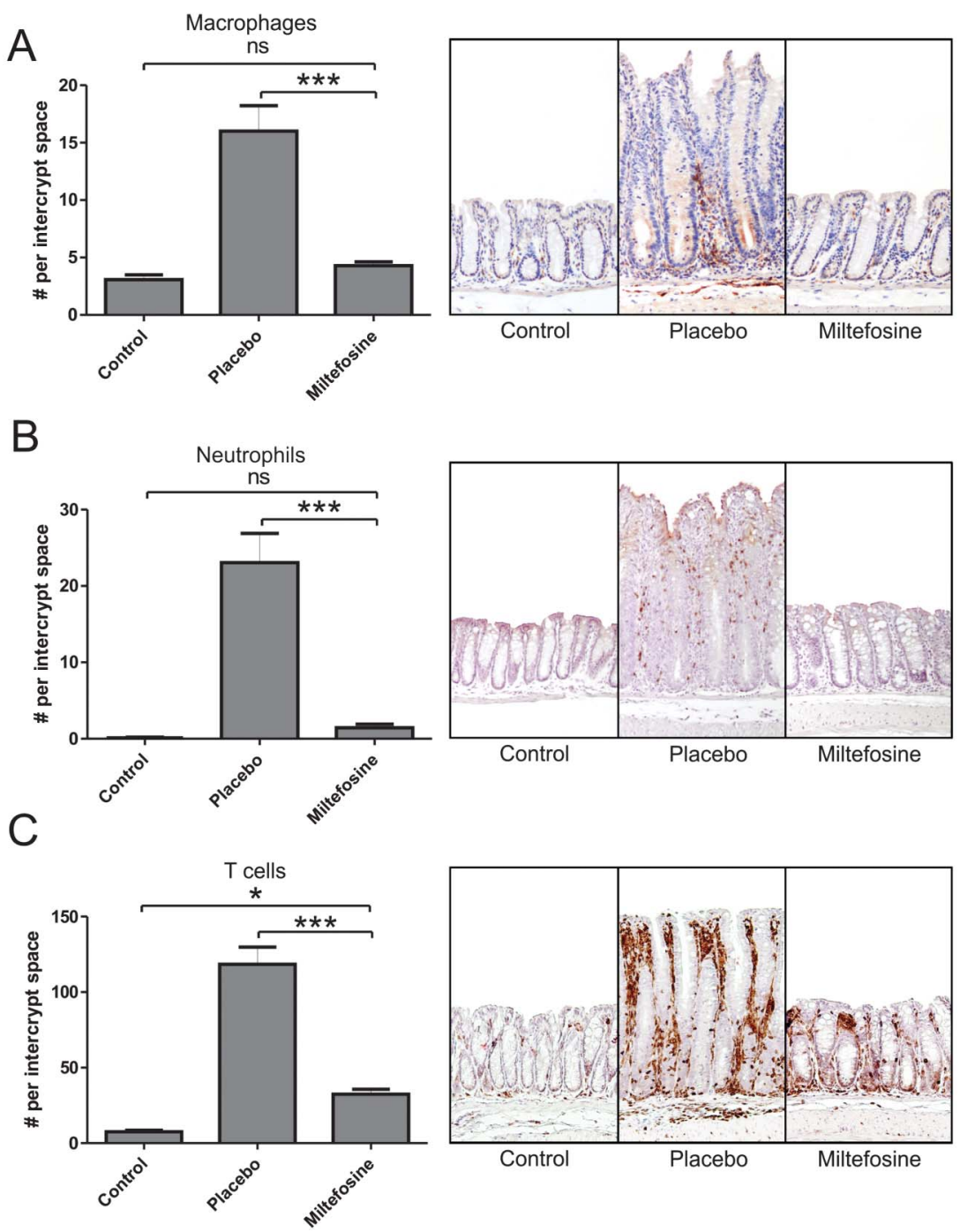

FIGURE 4. Reduced influx of different leukocyte subsets in miltefosine-treated animals. A, Quantification and representative images of the presence of macrophages as determined by immunohistochemistry for F4/80. B, Quantification and representative images of the presence of neutrophils as determined by immunohistochemistry for Ly6G. C, Quantification and representative images of the presence of T cells as determined by immunohistochemistry for CD3. Control $=C D 4+C D 45 R B^{\text {high+low }}$, placebo $=C D 4{ }^{+} C D 45 R B^{\text {high }}+$ placebo, miltefosine $=C D 4+C D 45 R B^{\text {high }}$ + miltefosine. Original magnifications $\times 100 .{ }^{*} P<0.05,{ }^{* * *} P<0.001$.

These results confirm the previous observation that miltefosine inhibits proliferation of $\mathrm{T}$ cells and suggests that miltefosine may suppress proliferation of $\mathrm{T}$ cells in conditions that cause steroid resistance.

\section{Miltefosine Suppresses Inflammation in the CD45RB ${ }^{\text {high }}$ Transfer Model}

To investigate if miltefosine might be a candidate immunomodulator for IBD, we used the experimental transfer colitis model. In this model, SCID mice are reconstituted with $\mathrm{CD} 4^{+} \mathrm{CD} 45 \mathrm{RB}^{\text {high }}$ cells. This population lacks the subset of $\mathrm{T}$ cells present in the $\mathrm{CD}^{+} \mathrm{CD} 45 \mathrm{RB}^{\text {low }}$ population that are required to suppress the development of colitis. ${ }^{18}$ We treated mice with a twice weekly dose of $50 \mathrm{mg} / \mathrm{kg}$ miltefosine by oral gavage. To allow the transferred $\mathrm{T}$ cells to home to the intestine and repopulate the mice, we started treatment with miltefosine at 2 weeks after adoptive transfer. Oral gavage with vehicle was used as a placebo treatment. In the course of 2 months, placebo-treated CD45RB ${ }^{\text {high }}$-transplanted SCID mice developed severe inflammation of the gut. Two mice died before the end of the experiment. One mouse in the miltefosine-treated group died due to a complication of the oral gavage. The other mouse was in the group of placebo mice and was taken out before the end of the experiment due to weight loss $>15 \%$. At completion of the experiment at day 60 , mice treated with miltefosine had lost significantly less weight than placebo-treated mice (Fig. 2A) suggesting a reduction in the severity of disease. Indeed, inspection of the colon showed that the colon of placebo-treated animals was severely affected, whereas colons of miltefosine-treated 

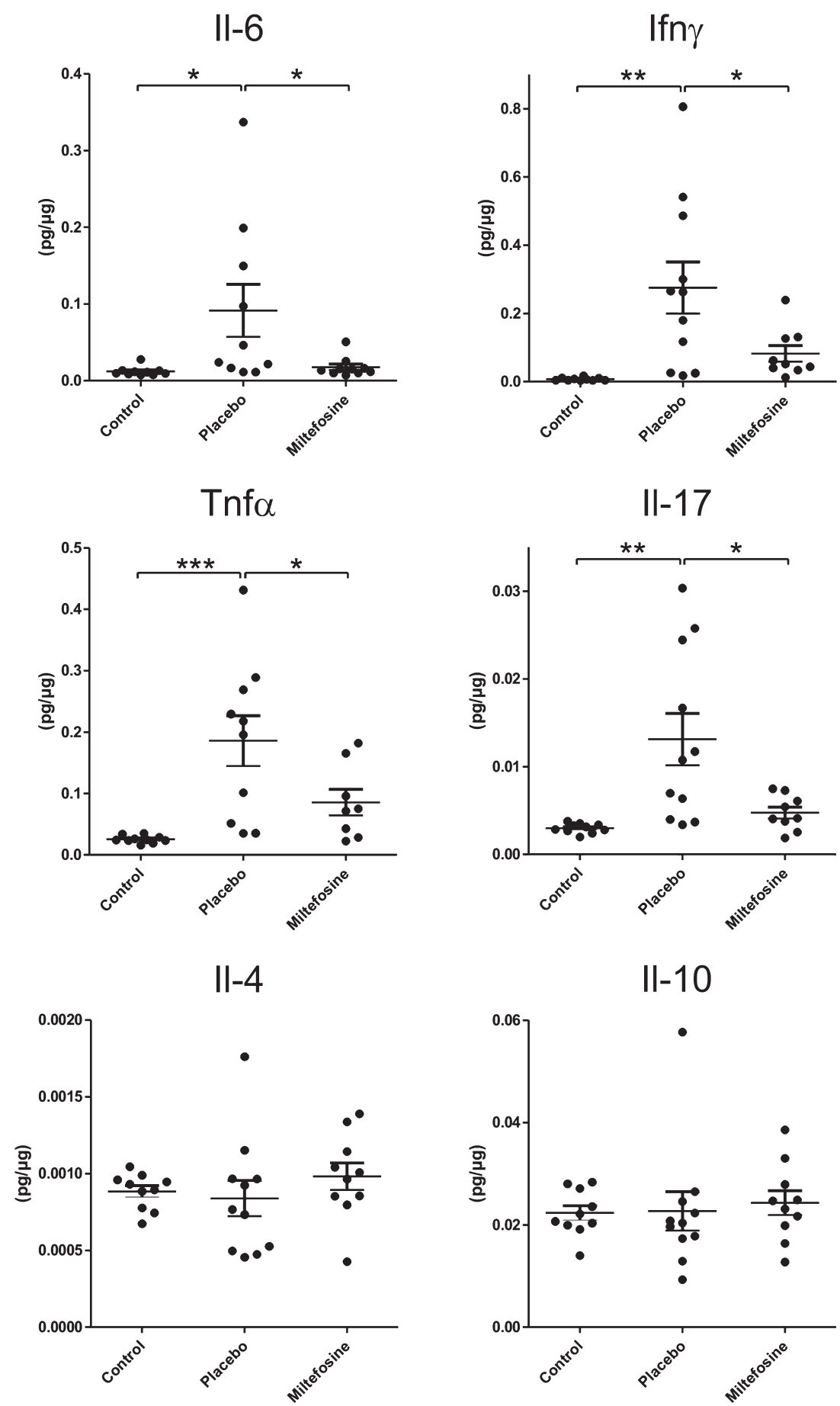

FIGURE 5. Miltefosine treatment reduces the production of proinflammatory cytokines. Measurement of mucosal levels of different cytokines in colonic homogenates by cytokine bead array. Control $=C D 4^{+} C D 45 R B^{\text {high+low }}$, placebo $=C D 4^{+} C D 45 R B^{\text {high }}+$ placebo, miltefosine $=C D 4{ }^{+} C D 45 R B$ high + miltefosine. $\mathrm{ns}=$ not significant, ${ }^{*} P<0.05$.

animals showed remarkably less edema and contained normal stool pellets (Fig. 2B). Treatment with miltefosine significantly reduced the disease activity index to levels comparable to controls (Fig. 2C). Colon weight was substantially increased in CD45RB ${ }^{\text {high }}$-reconstituted placebo-treated mice compared with control mice. Colon weight of miltefosine-treated mice was substantially reduced compared with placebo-treated animals and not significantly different from control mice that were reconstituted with both $\mathrm{CD} 45 \mathrm{RB}^{\text {high }}$ and $\mathrm{CD}^{4} 5 \mathrm{RB}^{\text {low }}$ cells (Fig. 2D). A similar observation was made for spleen weight which miltefosine treatment reduced to the level of the control group (Fig. 2E). 
To confirm the gross morphological examination at the histopathological level, coded H\&E-stained slides were examined by a blinded experienced gastrointestinal pathologist (S.L.M.) and the degree of inflammation was scored. Mice in the placebo-treated group showed clear infiltrates of leukocytes, loss of goblet cells, crypt damage, epithelial hyperplasia, ulcerations, and crypt abcesses (Fig. 3A-C). In contrast, in the mucosa of mice that were treated with miltefosine, all aspects of inflammation were significantly reduced compared with placebo-treated mice (Fig. 3A-C). None of the histopathological hallmarks of colitis in the miltefosine-treated animals was significantly different from control animals without colitis (Fig. 3A).

We subsequently analyzed the recruitment of individual leukocyte subsets to the mucosa (Fig. 4). We used F4/80 as a marker of macrophages, Ly6G for neutrophils, and CD3 for $\mathrm{T}$ cells. The number of infiltrating cells of each type was counted per intercrypt space. Per mouse, 9 intercrypt spaces were counted in 3 high-power field images ( 3 adjacent intercrypt spaces per image). In placebo-treated animals with colitis, the number of infiltrating macrophages, neutrophils, and T cells was substantially increased compared with controls. Treatment with miltefosine significantly reduced influx of all 3 cell types. Both macrophage and neutrophil infiltration were not significantly different from unaffected control animals (Fig. 4A-C).

To investigate the immunomodulatory effect of miltefosine treatment on cytokine production, cytokine levels were determined in whole colon lysates (Fig. 5). In the colitis group, the inflammation caused a significant increase in the levels of the proinflammatory cytokines IL-6, TNF- $\alpha$, interferon- $\gamma$, and IL-17. The levels of the Th2-related cytokine IL-4 and of the anti-inflammatory cytokine IL-10 remained unchanged. In mice treated with miltefosine, the increase of proinflammatory cytokines IL- 6 , TNF- $\alpha$, interferon- $\gamma$, and IL-17 was significantly reduced.

\section{DISCUSSION}

Miltefosine was initially developed as an anticancer drug but has largely failed clinical development for oncology. After preclinical experiments in mice, ${ }^{6}$ it was found that miltefosine has a surprising efficacy for the treatment of leishmaniasis. ${ }^{7,8}$ Since it was previously found that miltefosine may suppress T-cell activation, ${ }^{11,12}$ we investigated miltefosine as a potential immunomodulator in a mouse model of colitis. We found that miltefosine efficiently inhibited PHA-mediated T-cell proliferation at physiologically attainable concentrations. ${ }^{9}$ In addition, miltefosine fully inhibited SEB-induced T-cell proliferation which is known to be only partially sensitive to dexamethasone. To test the feasibility of miltefosine treatment as a way to suppress intestinal inflammation, we used the experimental $\mathrm{CD} 4^{+} \mathrm{CD} 45 \mathrm{RB}^{\text {high }}$ transfer colitis mouse model. We chose this model as it is characterized by an expression profile of proinflammatory molecules that is relatively similar to human IBD, especially compared with the chemical colitis models. ${ }^{19}$ Treatment with miltefosine was started 2 weeks after the T-cell transfer because in previous studies which used this model, the mice started losing weight after those first 2 weeks. ${ }^{20}$ The mice were dosed $50 \mathrm{mg} / \mathrm{kg}$ twice per week as miltefosine has a long halflife. Treatment with miltefosine resulted in a remarkable reduction of all aspects of the severity of colitis that we examined. Most of the hallmarks of colitis that we measured in this model were no longer significantly different between $C D 45 R^{\text {high }}$-transplanted colitic mice treated with miltefosine and control mice that received both $\mathrm{CD} 45 \mathrm{RB}^{\text {high }}$ and $\mathrm{CD} 45 \mathrm{RB}^{\text {low }}$ cells.

As miltefosine is already marketed for use in leishmaniasis under the brand name Impavido (by Zentaris), it could be an attractive immunomodulator to examine for use in humans with IBD. Miltefosine has an excellent oral availability, and the pharmacokinetics have been well described. ${ }^{9}$ Clinical trials in humans have shown an acceptable safety profile with reversible abnormalities in liver biochemistry and renal function. ${ }^{7,8}$ The major side effects of miltefosine are nausea and vomiting which could be problematic in patients with IBD. However, these side effects are often transient. ${ }^{7,8}$ The safety and side effects of longterm miltefosine use that would be required for maintenance therapy in patients with IBD have not been established.

In conclusion, we found that miltefosine inhibits T-cell proliferation at physiologically relevant concentrations in vitro. Miltefosine strongly reduced severity of colitis in the murine transfer model of colitis. Our data suggest that miltefosine is an interesting candidate anti-inflammatory drug for patients with IBD.

\section{REFERENCES}

1. Verweij J, Planting A, van der BM, et al. A dose-finding study of miltefosine (hexadecylphosphocholine) in patients with metastatic solid tumours. J Cancer Res Clin Oncol. 1992;118:606-608.

2. Planting AS, Stoter G, Verweij J. Phase II study of daily oral miltefosine (hexadecylphosphocholine) in advanced colorectal cancer. Eur J Cancer. 1993;29A:518-519.

3. Verweij J, Krzemieniecki K, Kok T, et al. Phase II study of miltefosine (hexadecylphosphocholine) in advanced soft tissue sarcomas of the adultan EORTC Soft Tissue and Bone Sarcoma Group Study. Eur J Cancer. 1993;29A:208-209.

4. Verweij J, Gandia D, Planting AS, et al. Phase II study of oral miltefosine in patients with squamous cell head and neck cancer. Eur J Cancer. 1993; 29A:778-779.

5. Leonard R, Hardy J, van TG, et al. Randomized, double-blind, placebocontrolled, multicenter trial of $6 \%$ miltefosine solution, a topical chemotherapy in cutaneous metastases from breast cancer. J Clin Oncol. 2001; 19:4150-4159.

6. Kuhlencord A, Maniera T, Eibl H, et al. Hexadecylphosphocholine: oral treatment of visceral leishmaniasis in mice. Antimicrob Agents Chemother. 1992;36:1630-1634.

7. Jha TK, Sundar S, Thakur CP, et al. Miltefosine, an oral agent, for the treatment of Indian visceral leishmaniasis. N Engl J Med. 1999;341: 1795-1800.

8. Sundar S, Rosenkaimer F, Makharia MK, et al. Trial of oral miltefosine for visceral leishmaniasis. Lancet. 1998;352:1821-1823.

9. Dorlo TP, van Thiel PP, Huitema AD, et al. Pharmacokinetics of miltefosine in Old World cutaneous leishmaniasis patients. Antimicrob Agents Chemother. 2008;52:2855-2860.

10. Barratt G, Saint-Pierre-Chazalet M, Loiseau PM. Cellular transport and lipid interactions of miltefosine. Curr Drug Metab. 2009;10: 247-255.

11. Baumer $\mathrm{W}$, Wlaz $\mathrm{P}$, Jennings $\mathrm{G}$, et al. The putative lipid raft modulator miltefosine displays immunomodulatory action in T-cell dependent dermal inflammation models. Eur J Pharmacol. 2010;628:226-232. 
12. Dolle S, Hoser D, Rasche C, et al. Long-term reduction in local inflammation by a lipid raft molecule in atopic dermatitis. Allergy. 2010;65: $1158-1165$.

13. Read S, Powrie F. Induction of inflammatory bowel disease in immunodeficient mice by depletion of regulatory T cells. Curr Protoc Immunol. 2001; Chapter 15:Unit.

14. Valentine MA, Tsoukas CD, Rhodes G, et al. Phytohemagglutinin binds to the 20-kDa molecule of the T3 complex. Eur J Immunol. 1985;15: 851-854.

15. Fraser JD, Proft T. The bacterial superantigen and superantigen-like proteins. Immunol Rev. 2008;225:226-243.

16. Hauk PJ, Hamid QA, Chrousos GP, et al. Induction of corticosteroid insensitivity in human PBMCs by microbial superantigens. J Allergy Clin Immunol. 2000;105:782-787.
17. Katzen D, Chu E, Terhost C, et al. Mechanisms of human T cell response to mitogens: IL 2 induces IL 2 receptor expression and proliferation but not IL 2 synthesis in PHA-stimulated T cells. J Immunol. 1985;135:18401845.

18. Alyanakian MA, You S, Damotte D, et al. Diversity of regulatory CD4+ T cells controlling distinct organ-specific autoimmune diseases. Proc Natl Acad Sci U S A. 2003;100:15806-15811.

19. te Velde AA, de Kort F, Sterrenburg E, et al. Comparative analysis of colonic gene expression of three experimental colitis models mimicking inflammatory bowel disease. Inflamm Bowel Dis. 2007;13:325-330.

20. Morrissey PJ, Charrier K, Braddy S, et al. CD4+ T cells that express high levels of CD45RB induce wasting disease when transferred into congenic severe combined immunodeficient mice. Disease development is prevented by cotransfer of purified CD4+ T cells. J Exp Med. 1993;178:237-244. 